\title{
Influence of Urbanization Factors on Surface Urban Heat Island Intensity: A Comparison of Countries at Different Developmental Phases
}

\author{
Yaoping Cui ${ }^{1}$, Xinliang $\mathrm{Xu}^{2, *}$, Jinwei Dong ${ }^{2}$ and Yaochen $\mathrm{Qin}^{1}$ \\ 1 Collaborative Innovation Center for the "Three Modernization" Harmonious Development of Central Plains \\ Economic Region, The College of Environment and Planning, Henan University, Kaifeng 475004, China; \\ cuiyp@lreis.ac.cn (Y.C.); qinyc@henu.edu.cn (Y.Q.) \\ 2 Institute of Geographic Sciences and Natural Resources Research, Chinese Academy of Sciences, \\ Beijing 100101, China; dongjw@1reis.ac.cn \\ * Correspondence: xuxl@lreis.ac.cn; Tel.: +86-10-6488-9038
}

Academic Editor: Tan Yigitcanlar

Received: 27 May 2016; Accepted: 18 July 2016; Published: 25 July 2016

\begin{abstract}
Urbanization is a global problem with demographic trends. The urban heat island plays a dominant role in local climate systems. Despite existing efforts to understand the impacts of multiple urbanization factors on the urban heat island globally, very little is known about the attribution of urban heat island magnitude to urbanization in different locations or developmental phases. In this study, based on global land surface temperature data, urban spatial domain data, gross domestic product (GDP), and population data, we analyzed the influence of multiple urbanization factors on global surface urban heat island intensity (SUHII). We also tentatively compared the abovementioned factors between different regions across the globe, especially between China and the USA, the largest countries that are experiencing or have experienced rapid urbanization in recent decades. The results showed that global SUHII had remarkable spatial heterogeneity due to the geographical and socioeconomic variation between cities. There was a significant correlation between SUHII and population as well as GDP in global cities. Moreover, this study suggested that the impacts of population on SUHII might be stronger in the early stages of urbanization, and the GDP factor would become a critical factor at a certain development level. The urban area also had non-ignorable impacts on SUHII, while the correlation between SUHII and urban shape was relatively weak. All these may imply that the best approach to slow down SUHII is to find other solutions, e.g., optimize the spatial configuration of urban internal landscapes, when the urbanization reaches a high level.
\end{abstract}

Keywords: MODIS; space-for-time; SUHII; China; USA

\section{Introduction}

Urbanization has an important impact on the environment. Although cities cover a tiny fraction of the world's surface, urban areas are the nexus of human activity, with more than $50 \%$ of the global population and $7 \%-90 \%$ of economic activity [1]. Urbanization changes climatic systems, threatens biodiversity, and affects ecosystem productivity through disturbing energy balance and habitats and the loss of carbon storage and biomass $[2,3]$. In fact, against the backdrop of climate change, cities have been regarded as ideal natural laboratories for global change studies, particularly valuable in elucidating future climate and environmental change as cities experience elevated temperatures decades ahead of the projected average global warming [4]. Developed countries can also be regarded as "harbingers" of the future urban warming of developing countries.

Urbanization has a strong influence on regional climate. As the core area of human activity, cities not only affect regional land use and land cover change (LUCC) but also affect global climate 
change [5]. Cities and their surrounding regions tend to experience intensive LUCC due to faster urban sprawl, more population, and intense human activities. Land surface and atmosphere together create an interactive system. A large number of artificial architectural landscapes and impervious surfaces replace the natural underlying surface (farmland, grassland, etc.). Based on the processes of changing surface energy balance and thermal properties, urbanization leads to a significant influence on local and regional climate [6]. Climatic differences, especially the temperature difference between urban and rural areas, always appear and keep increasing with urban sprawl and human aggregation. Alavipanah et al. (2015) estimated the role of vegetation in mitigating urban land surface temperatures against the backdrop of rapid urbanization. The results of the study demonstrated that land surface temperature (LST) within urban vegetation was also affected by the temperature of the surrounding built-up areas, and suburban areas were cooler than the core of the urbanized region [7]. Therefore, in almost every aspect, accelerating urbanization will lead to a profound impact on local and regional climate, and the urban heat island (or surface UHI) effect is one of the most well-known phenomena caused by urbanization $[8,9]$.

Urbanization includes many different factors, and many types of urban indexes can be used to indicate the process of urbanization. However, when we focus on the research theme of urbanization and the urban heat island, almost all of these urbanization factors, no matter the source, can be placed into three categories: population, economy, and spatial domain. The three basic factors are interrelated and are always used together to describe urbanization or urban sprawl [10]. Now when we discuss urbanization, many aspects, like population, economy, and area are included. Therein, population is a common factor and is widely used to define the urbanization level and urbanization rate. Oke (1973) used population to describe the urban size. In his study, he linked the observed air temperature data and population to study the urban heat island (UHI) effect in 11 European cities. In addition, a significant logarithmic relationship between urban heat island intensity and population was obtained [11]. Jones and Karl found there was a certain non-linear relationship between population and urban heat island intensity. They also assessed the effect of urbanization on air temperature and regional differences appeared in their study [12]. In fact, more and more studies have shown that UHI have relationship with the urbanization factors, like population, economy, city size, geometric characteristics, and so on [12-14]. In recent years, some studies have focused on the impact of spatial landscape configuration on urban heat island intensity [6]. Relative to LST differences of urban and rural areas, many studies focused on establishing the relationship between the urban space shape and LST [15-18]. At the landscape level, Li et al. (2011) reported that more patch density would bring higher LST and more diversity might bring lower LST [19]. Zhou et al. demonstrated (2011) that although the composition of urban surface cover types had more impact than their configuration on LST, the spatial shapes of urban surface types also significantly impacted urban LST [20]. These studies analyze the impacts of the spatial arrangement of urban landscape and percentage of urban composition on LST [21]. Therefore, it is necessary to consider the effects of urban landscape when examining the effects of urban sprawl on LST [6].

Some studies focused on the effects of urbanization on the temperature in a typical region or certain cities [4,22]. However, a single analysis of urban space sprawl, population, or economic factors cannot reveal the complex relationship between urbanization and UHII. Moreover, studies from different time periods showed that these results may be hard to directly compare with each other. Some studies attempted to reveal the impacts of human-induced urbanization on regional climate all over the world [23-25]. Jin et al. (2005) investigated urban temperatures on a global scale, but they did not measure heat differentials or relate them to any other variable [26]. Peng et al. (2012) assessed the diurnal and seasonal variation of SUHII across 419 global big cities, and simply assessed several potential biophysical and socioeconomic driving factors. However, they neglected spatial variability at the sub-metropolis scale [27]. The rural areas around cities will direct the SUHII results. Although Clinton et al. (2013) have detected the SUHII difference with different rural areas, the method used to define the urban and rural areas meant that it was hard to effectively distinguish the complex 
footprint of different cities [28]. Moreover, some studies have shown that the related results will differ significantly depending on the different data used to classify urban and rural areas [29-32].

Despite the fact that many studies have focused on the impact of multiple urbanization factors on SUHII globally, there are still large discrepancies among these studies and uncertainty exists about the results. Therefore, this study uses Moderate Resolution Imaging Spectroradiometer (MODIS) LST production, global urban spatial data, population, and gross domestic product (GDP) to analyze the influence of different urbanization factors on the urban heat island during different development phases. In the process, a new threshold method was proposed to distinguish the rural areas. We also compared the difference among different countries, especially China and the USA-the largest countries that are experiencing or have experienced rapid urbanization in the last decades. This study aims to answer the following questions: (1) What is the distribution pattern of global SUHII? (2) What are the relationships between urbanization factors and surface LST on a global scale? and (3) In different cities with different development levels or phases, are the impacts of urbanization factors on SUHII the same or similar?

\section{Data and Methods}

The data used in this study included LST [33], global city space extent data [1], population, and GDP data [34]. The global urban spatial data for 2001-2002 came from the SAGE Center (Center for Sustainability and the Global Environment, University of Wisconsin-Madison, USA), which used an ensemble decision tree classification approach to create the high-resolution urban land cover data based on MODIS $500 \mathrm{~m}$ spatial resolution data. The MODIS global LST data of 2003 was obtained from the online Data Pool maintained by the NASA EOSDIS Land Processes Distributed Active Archive Center (LP DAAC), USGS/Earth Resources Observation and Science (EROS) Center, Sioux Falls, South Dakota, USA. The global population data was from the World Urbanization Prospects and Population and Vital Statistics Report. The report on global urban and rural population was issued by the Population Division of the United Nations [35].

The urban and rural boundaries always decide the precision of the research results. In fact, it is hard to demarcate accurately. In order to assess urbanization impacts on urban temperature, based on the spatial analysis of buffers, we combine a threshold value method to confirm the final urban and rural areas. Additionally, urban heat island intensity was described as the highest temperature difference between a city and its surrounding countryside [11]. Our previous study had confirmed that the highest and average LST in a city and its rural areas had a significantly high linear relationship (correlation coefficient, $r=0.93$ ) [36]. Therefore, in the study, SUHII was defined as the mean LST difference between urban and rural areas.

The data processes are shown in Figure 1. Following the elemental definition, rural spaces were based on six spatial buffers of cities $(0-5 \mathrm{~km}, 5-10 \mathrm{~km}$, etc.), namely the surrounding rural areas of cities. A threshold of the LST difference $\left( \pm 0.2^{\circ} \mathrm{C}\right)$ was used to determine the final buffers, which represent the different rural regions. Firstly, the buffer of $0-5 \mathrm{~km}$ was created because of the suburbs with mixed urban and rural areas, and the buffer was defined as the fixed suburban region between the city and the countryside. The prior order of the following buffers was $5-10 \mathrm{~km}, 0-10 \mathrm{~km}, 10-15 \mathrm{~km}$, $5-15 \mathrm{~km}$, and $0-15 \mathrm{~km}$. Then, we calculated the temperature differences between near two sequenced buffers. If the temperature difference was over the threshold of $0.2{ }^{\circ} \mathrm{C}$, the buffer area was only in the rural area. For example, if the absolute value of the LST difference between the $0-5 \mathrm{~km}$ buffer and the urban area was less than the threshold, the data process would continue. If the threshold (or more than the threshold) of the LST difference happened between the $0-5 \mathrm{~km}$ and 5-10 km buffers, then the 0-10 km buffer was considered as the rural area of the city. Due to this order, if the absolute value of the LST difference was more than $0.2{ }^{\circ} \mathrm{C}$, the corresponding buffer area meant the rural area. In an extreme situation, if all the LST differences of buffers could not be more than the threshold, then a buffer of $0-15 \mathrm{~km}$ is defined directly as the rural areas. 


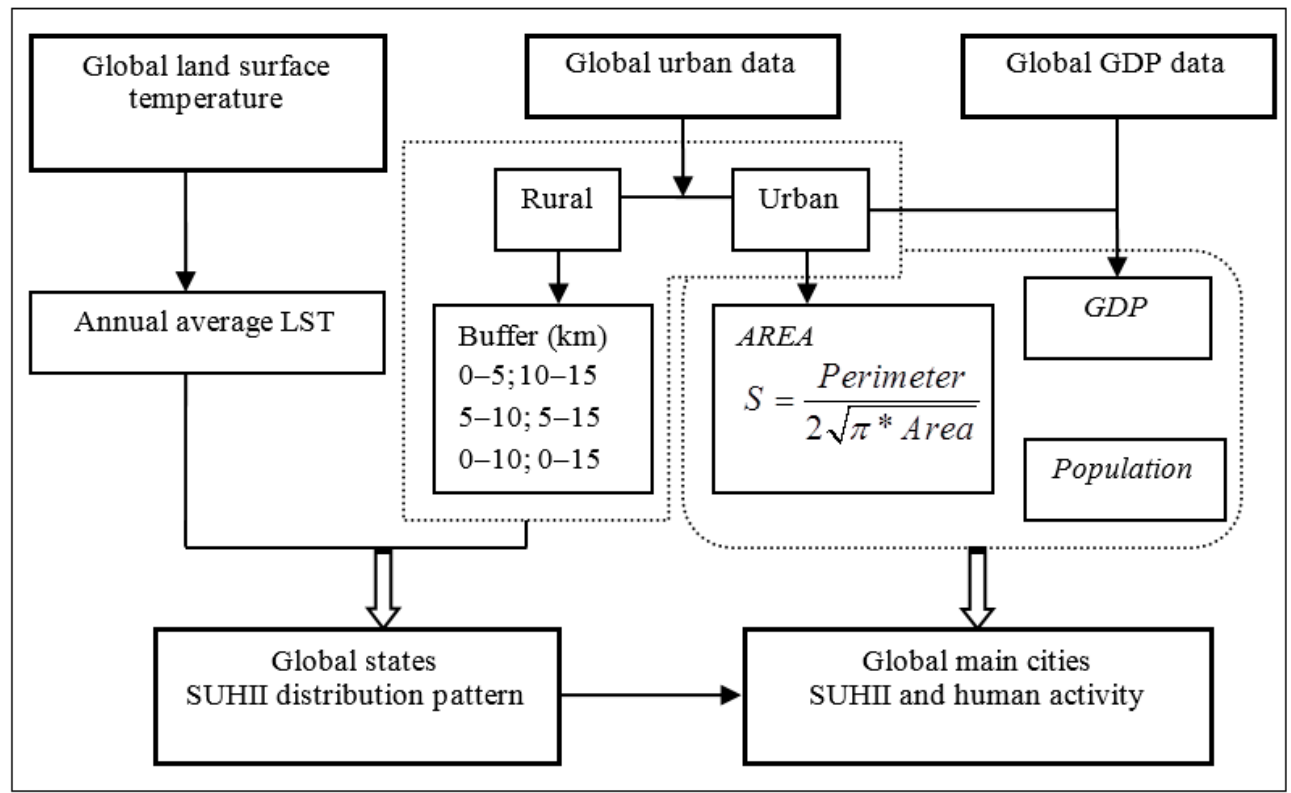

Figure 1. Flowchart of procedures of study.

Simultaneously, in order to analyze the relationship between SUHII and urbanization, four urban expansion factors were selected: namely, Population (a key urbanization factor), GDP (represents the level of economic activity), Area (a typical spatial factor, which is very suitable to define the level and scale of cities), and urban spatial index $S$ (the more complex or prolate the shape of patches, the greater the value of $S$ ).

\section{Results and Analysis}

\subsection{The Distribution Pattern of the SUHII}

Global distribution of SUHII was hard to show in one map as the proportion of urban areas was very small. Thus, we used a province administrative boundary as a base map to show the spatial pattern of the global SUHII at the province scale. Namely, all the SUHII values of cities in a province or state administrative region were averaged (Figure 2). The result showed that the distribution pattern of SUHII was significantly different with the spatial pattern of global LST because urban and nearby areas were significant influenced by human activities. Among the different regions, most cities showed warming situations except for several regions near the Equator or ocean, which had a small or even negative SUHII (Cool Island) [37]. The following reasons might contribute to these special situations. One possible reason was that the LST could not indicate the higher background temperature. Secondly, the ocean might have a moderating effect to temperature anomalies of coastal cities. Thirdly, some biophysical parameters, such as the albedo of the surface material types in urban areas, may be higher than in surrounding areas [2]. In addition, other climate factors like more clouds and precipitation also had an impact on the phenomenon.

SUHII varied in different urbanization areas. The higher SUHII values mostly did not appear in economically developed areas (Figure 2). As we know, higher surface temperature appears when humans aggregate in urban areas and change the natural land surface. Although the process of urbanization and its impacts on SUHII may be similar, the specific features-percentage, composition, and arrangement of land use and land cover types-in each city were various. Moreover, the specific developmental process, level, and phase were different in each country or region. Although the spatial pattern of SUHII indicated the complex results of urbanization, how should we interpret the relationship between SUHII and urbanization factors? What is the intrinsic reason of heterogeneity of SUHII? In order to explain the problem, this study selected 296 big cities of the world to analyze. 


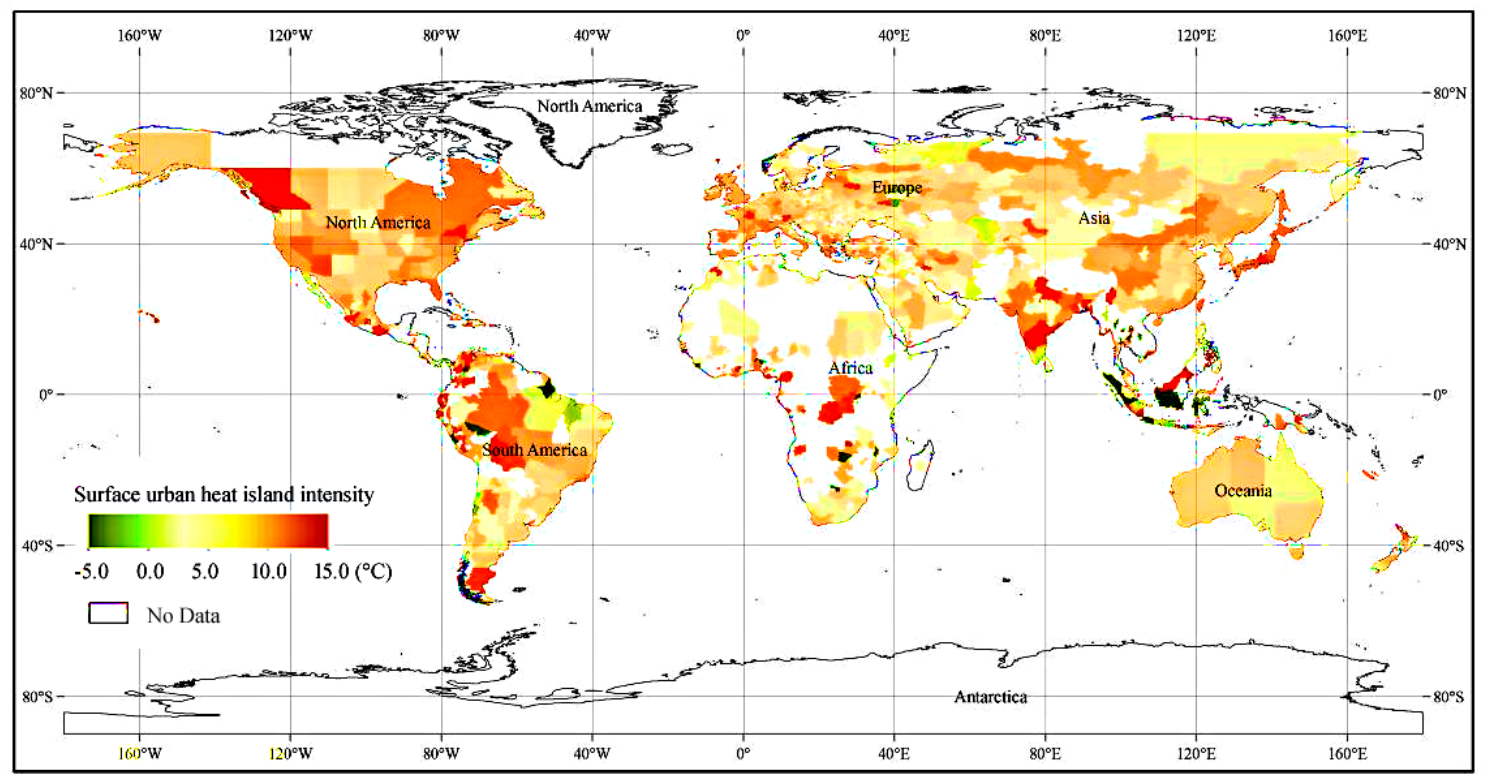

Figure 2. Spatial pattern of the global surface urban heat island intensity $\left({ }^{\circ} \mathrm{C}\right.$ ) (space unit: province/state).

\subsection{The Analysis of Global Cities}

SUHII may be remarkably high in cities with more economic activity and more population. In this section, 296 global cities spread over the world were chosen according to factors including the urban position (the capital, economic hub), population (the world's top 500), and built-up area. The Pearson correlation coefficients between the SUHII and urbanization factors are listed in Table 1. The results partially showed that SUHII had a significant relationship with population $(p=0.01), \operatorname{GDP}(p=0.01)$, and urban area $(p=0.05)$, but the correlation was insignificant with the urban shape $S$.

Table 1. The Pearson relationship of surface urban heat island intensity (SUHII) and various urbanization factors.

\begin{tabular}{ccccccccc}
\hline \multirow{2}{*}{$\begin{array}{c}\text { SUHII } \\
\text { (Sig.) }\end{array}$} & \multicolumn{2}{c}{ Global Cities $(\boldsymbol{n}=\mathbf{2 9 6})$} & \multicolumn{2}{c}{ Major Cities $^{\mathbf{1}}(\boldsymbol{n}=\mathbf{6 2})$} & \multicolumn{2}{c}{ China $^{\mathbf{1}}(\boldsymbol{n}=\mathbf{1 8})$} & \multicolumn{2}{c}{ USA $^{\mathbf{1}}(\boldsymbol{n}=\mathbf{2 9})$} \\
\cline { 2 - 8 } & $\boldsymbol{r}$ & Sig. & $\boldsymbol{r}$ & Sig. & $\boldsymbol{r}$ & Sig. & $\boldsymbol{r}$ & Sig. \\
\hline Population & 0.164 & 0.002 & 0.324 & 0.005 & 0.668 & 0.001 & 0.681 & 0.000 \\
GDP & 0.168 & 0.002 & 0.418 & 0.000 & 0.557 & 0.008 & 0.758 & 0.000 \\
Area & 0.103 & 0.039 & 0.349 & 0.003 & 0.579 & 0.006 & 0.650 & 0.000 \\
S & 0.025 & 0.337 & 0.138 & 0.142 & 0.350 & 0.077 & 0.454 & 0.007 \\
\hline
\end{tabular}

${ }^{1}$ The major cities are those whose built-up areas are greater than $500 \mathrm{~km}^{2}$. Eighteen cities in China and 29 cities in the USA were chosen, mainly located between $30^{\circ} \mathrm{N}$ and $45^{\circ} \mathrm{N}$.

The linear fitting method and four nonlinear fitting methods including logistic, inverse, quadratic, and cubic were used to analyze the attribution of SUHII. The results indicated that the SUHII values in most of the major cities of the world were less than $2.5^{\circ} \mathrm{C}$. There were 285 cities with SUHII less than $5.0{ }^{\circ} \mathrm{C}$, accounting for $96.3 \%$ of all the major cities in this study. Figure 3a meant the relationship between SUHII and the population. Generally, SUHII had a certain degree of logarithmic relationship with population (Figure 3b), but the fitting degree was low (maximum $R^{2}=0.046$, $p<0.001$ ). Correlations between SUHII and GDP, and SUHII and Area were present, while the shape index $S$ of cities still did not show a correlation with SUHII (Figure 3a-e). 


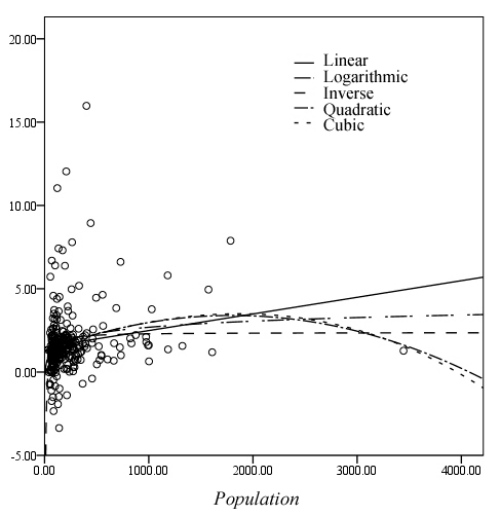

(a)

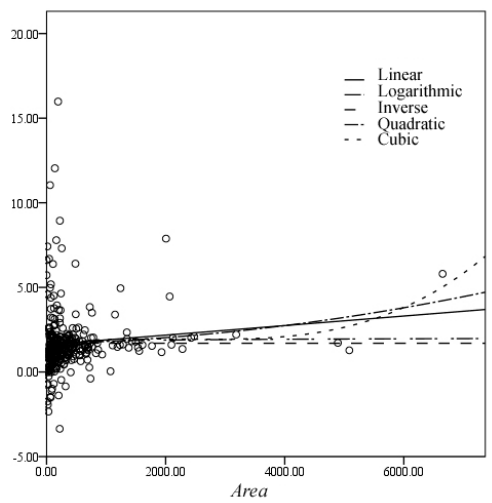

(d)

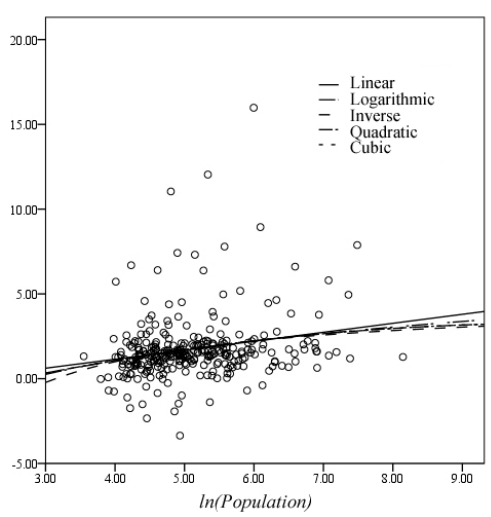

(b)

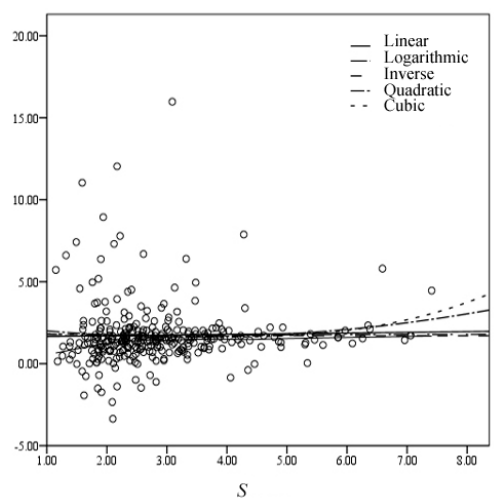

(e)

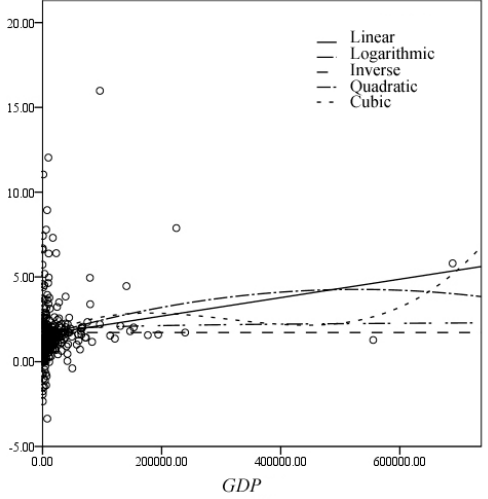

(c)

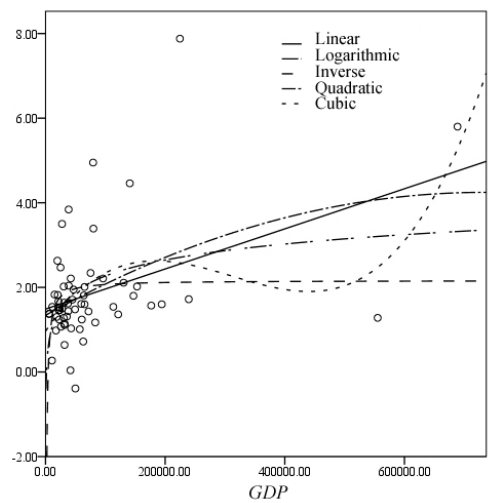

(f)

Figure 3. Partial fitting figures of the urban heat island intensity (SUHII) and urbanization factors. (a,b) Mean relationship between SUHII and population, and logarithmic population; (c-e) mean relationship between SUHII and the GDP, area, and urban shape index $S$, respectively; (f) the result of stepwise regression fitting with GDP.

On the global scale, there were no obvious rules to the distribution pattern of SUHII (Figure 2). We selected some typical samples from 62 major cities whose built-up areas were greater than $500 \mathrm{~km}^{2}$ to analyze the influence of urbanization factors on SUHII. Generally, the SUHII values of large cities are obvious, and the relationship between SUHII and urbanization factors is clear. The results of Pearson correlation analysis showed that the SUHII and GDP, population, and urban area all showed a certain correlation, with correlation coefficients of $0.42,0.32$, and 0.42 , respectively (Table 1 ). These results were similar to the results from the global cities, and the correlation coefficients were bigger. Moreover, the effect of population on SUHII was stronger than that of GDP. The stepwise regression analysis also confirmed the result (the whole fitting degree was $0.175, p<0.01$ ). In particular, Figure $3 f$ shows the result of stepwise regression fitting, in which the best fitting coefficient reached 0.24 with the cubic fitting method $(p<0.01)$.

In short, it is hard to find rules that apply to all 296 cities, but in the selected major cities, SUHII is significantly related with GDP, population, and urban area, while the relationship between SUHII and $S$ was insignificant.

\subsection{Comparison Analysis on China and the United States}

In order to explore the regional SUHII, 18 cities in China and 29 cities in the United States, mainly located at $30-45^{\circ} \mathrm{N}$, were chosen to analyze the relationship between SUHII and urbanization factors (Figure 4). These cities had similar urbanization attributes (namely, all are regional centers and have huge areas and populations), but they had various urbanization levels and were in different developmental phases. Analyzing major cities in China and the United States, the 
largest countries that are experiencing or have experienced rapid urbanization in recent decades, could help with understanding the SUHII of various countries or regions at different urbanization developmental phases.

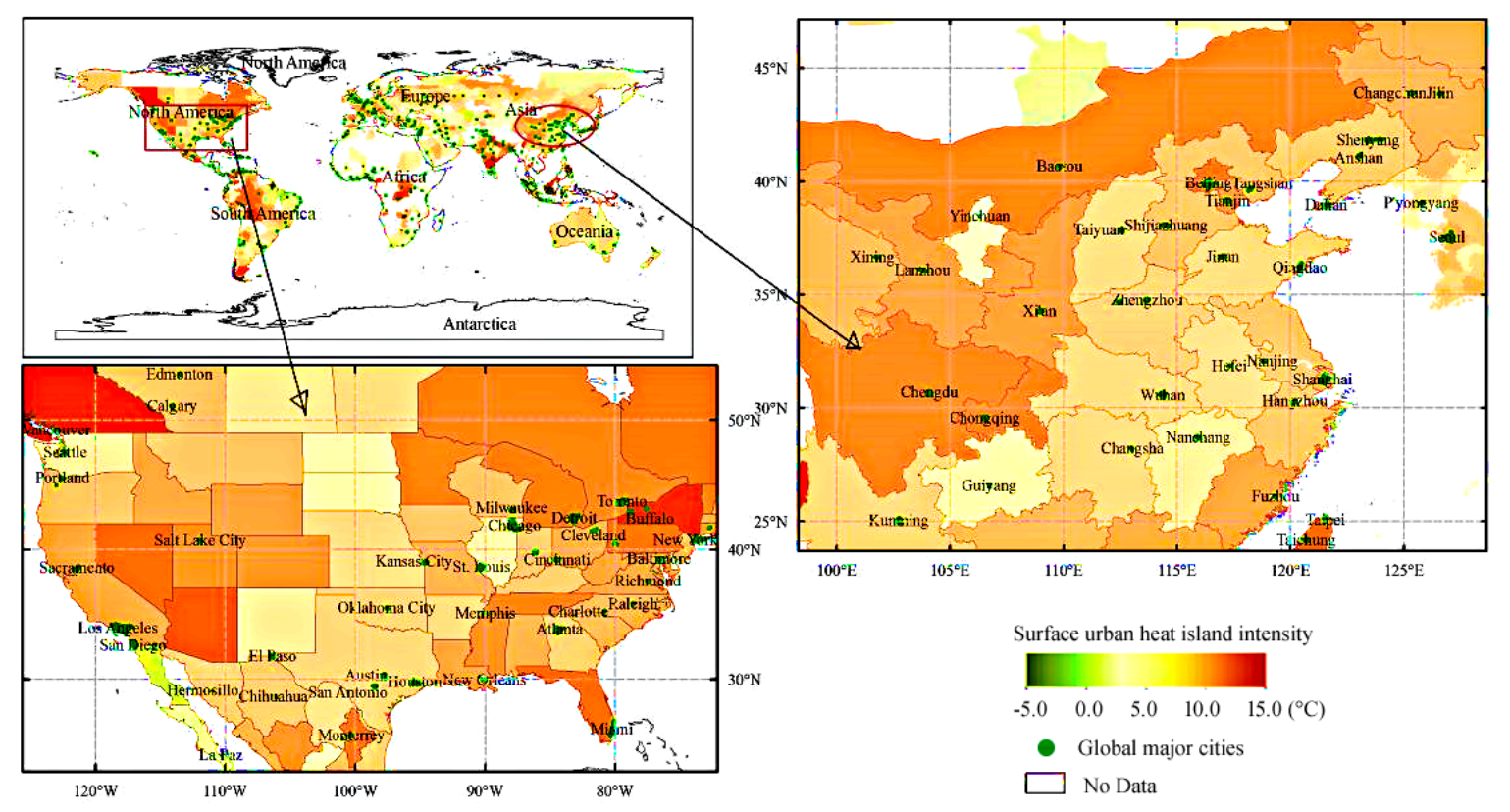

Figure 4. Main cities and their surface urban heat island intensity $\left({ }^{\circ} \mathrm{C}\right)$ in China and the USA. China (18): Shanghai, Shenyang, Anshan, Baotou, Beijing, Tangshan, Hangzhou, Shijiazhuang, Taiyuan, Jinan, Zhengzhou, Xi'an, Hefei, Chengdu, Tianjin, Dalian, Lanzhou, Nanjing; USA (29): New York, Boston, Richmond, Los Angeles, San Diego, Baltimore, Portland, Toronto, Milwaukee, Buffalo, Detroit, Washington, Chicago, Cleveland, Pittsburgh, Salt Lake City, Indianapolis, Cincinnati, Kansas City, St. Louis, San Francisco, Raleigh, Oklahoma City, Charlotte, Memphis, Atlanta, El Paso, Austin, Houston.

Both in China and the United States, there were significant relationships between SUHII and population, GDP, and area, while, the relationship between SUHII and urban shape was relatively weak. In terms of China, the results of linear stepwise regression also indicated that population, the main urbanization factor, was also a main impact factor on SUHII (SUHII $=1.402+0.001$ * population, $\left.R^{2}=0.446\right)$. In terms of the United States, GDP was the maximum correlation coefficient $(r=0.76)$. These results were similar to the results from major global cities, indicating that urban population, GDP, and area all had important impacts on SUHII (Table 1). GDP may replace population as the primary factor when urban development reaches a certain level or stage.

We compared the SUHII values in major cities of China with those of the USA; the detail fitting maps are shown in Figure 5. It can be seen that SUHII values in China were between 1.2 and $1.8^{\circ} \mathrm{C}$, while the SUHII values in most cities of the USA were between 1.0 and $2.0^{\circ} \mathrm{C}$. The fitting results in China were more complex. This may be associated with the various development forms and levels, and urban sprawl patterns. Moreover, we found that the SUHII values presented logarithmic relationships with the human economic activity intensity indexes in China, but had an exponential relationship with the urban Area and shape index $S$ (Figure 5a-d). However, the situation in the USA was simple. The cities in China and USA all showed a liner correlation between SUHII and population, GDP, and Area. On the other hand, city shape index was expressed better by a nonlinear quadratic function than by a linear one (Figure $5 \mathrm{e}-\mathrm{h}$ ). 


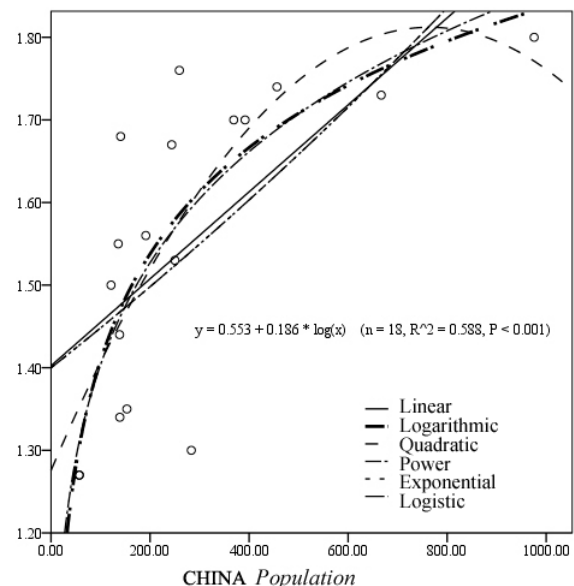

(a)

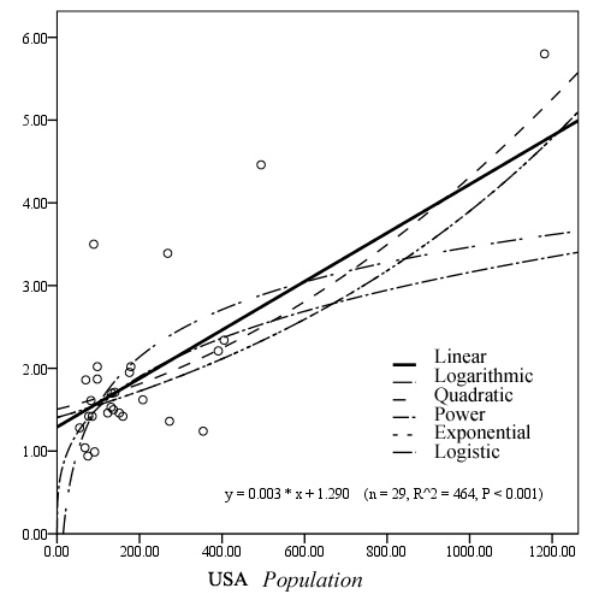

(e)

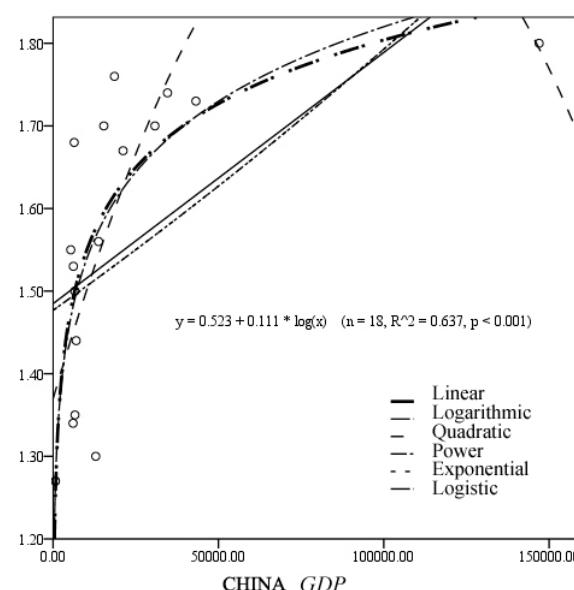

(b)

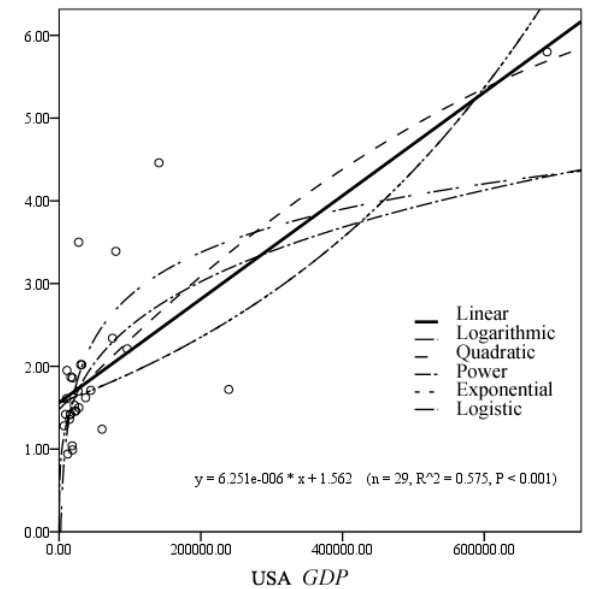

(f)

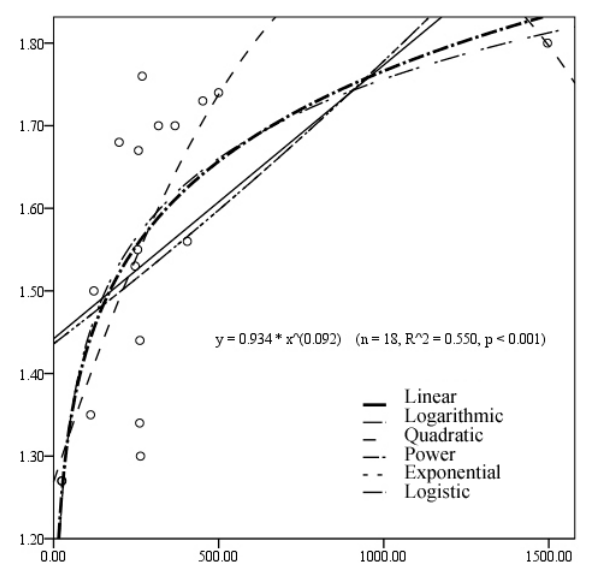

(c)

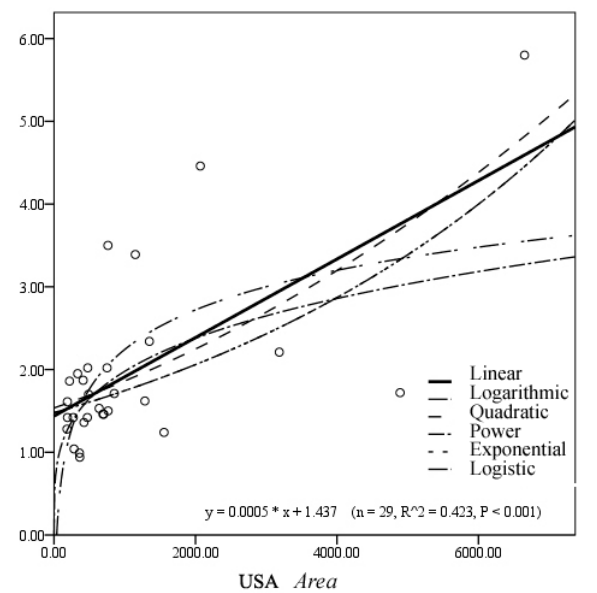

(g)

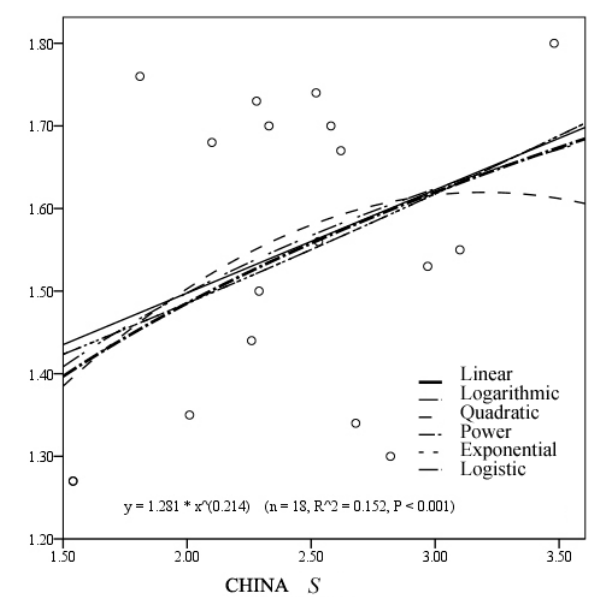

(d)

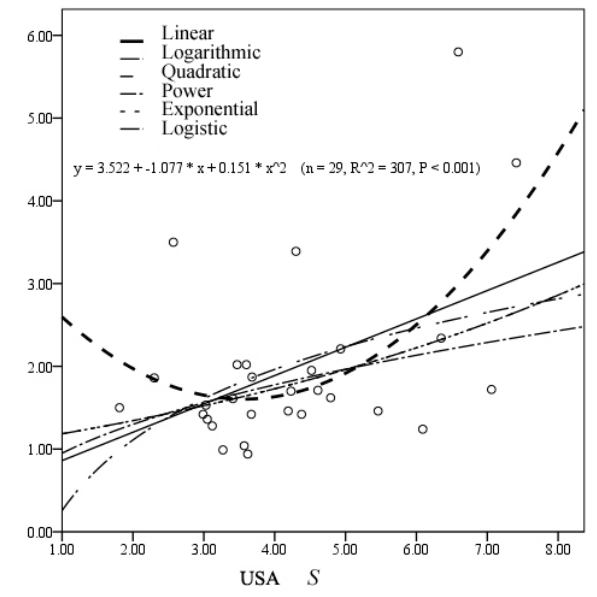

(h)

Figure 5. Partial fitting figures of SUHII values and urbanization factors in China and the USA. (a-d) Mean relationship between SUHII and population, GDP, Area, and urban shape index $S$ in China; (e-h) mean relationship between SUHII and population, GDP, area, and shape index $S$ in the USA, respectively. 
In order to effectively analyze the interactions and different impacts of the four urbanization factors, we also used the statistical method of multiple linear regression. Although the multiple $r$ in China and the USA all showed that there was obvious correlation between SUHII values and urbanization factors $(r$ (China) $=0.75$ and $r($ USA $)=0.77)$, adjusted fitting coefficient $\left(R^{2}\right)$ showed the four factors only represented $38 \%$ and $53 \%$ in China and USA, respectively. The regression results for the USA passed the significance test $(F=0.0003)$, while the results of China did not pass the significance test $(F=0.064)$, which indicates that a very complicated urbanization exists in China. The basic weights or impacts of urbanization factors on SUHII could be represented by the standardized coefficients (beta), although the statistical correlation of most factors both in China and the USA were not significant (Table 2). Additionally, the population in China and GDP in the USA all passed the significance test. The results were similar to the results of correlation analysis, showing that the urbanization factor had an important impact on SUHII in the two countries.

Table 2. The standardized coefficients of multiple linear regression.

\begin{tabular}{ccccccc}
\hline & \multicolumn{3}{c}{ China } & \multicolumn{2}{c}{ USA } \\
\cline { 2 - 7 } & $\begin{array}{c}\text { Unstandardized } \\
\text { Coefficients (B) }\end{array}$ & $\begin{array}{c}\text { Standardized } \\
\text { Coefficients (Beta) }\end{array}$ & Sig. & $\begin{array}{c}\text { Unstandardized } \\
\text { Coefficients (B) }\end{array}$ & $\begin{array}{c}\text { Standardized } \\
\text { Coefficients (Beta) }\end{array}$ & Sig. \\
\hline Constant & 1.391 & 6.427 & 1.257 & & 0.031 \\
Area & 0.0001 & 0.208 & 0.869 & -0.0003 & -0.427 & 0.438 \\
S & -0.027 & -0.081 & 0.806 & 0.128 & 0.170 & 0.485 \\
Population & 0.001 & 1.715 & 0.042 & -0.0003 & -0.061 & 0.931 \\
GDP & $-5.758 \times 10^{-6}$ & -1.244 & 0.326 & $9.151 \times 10^{-6}$ & 1.110 & 0.014 \\
\hline
\end{tabular}

\section{Discussion}

\subsection{The Importance of Uniform Analysis Scale}

Urban spatial data had great influence on the accuracy of the overall results in this study. Chen et al. (2015) created two datasets based on new global urban land cover mapping in 2000 and 2010 [38]. However, the high spatial resolution $(30 \mathrm{~m})$ of the data is so high that some fragmentation of urban areas always occurs on the global analysis scale. MODIS land cover production provides the urban and urban-related spatial data, but it cannot be used to do time-series studies due to its internal restriction. Global impervious surface data is made by inputting Nighttime Lights \& LandScan data, while the data of 2000 still hardly compares with the data of 2010 directly because of the difference between coarse and fine resolution [39]. However, it is very difficult to differentiate between urban and rural areas. In fact, the urban land includes the urban land and urban teleconnections land (urban-impact areas) [3]. Considering the general definitions of urban land, currently there are three different results [40]. One of the definitions is "urban area", delineated by administrative boundaries; another is "built-up area", dominated by artificial surfaces; and the third term is "impervious surface", which refers to human-made land covers that water cannot penetrate [41,42]. So, if we want to assess the urban sprawl or SUHII, we must choose a suitable urban data. In this study, we considered the urban data problem and finally chose the global urban data with a $500 \mathrm{~m}$ resolution [1].

The singular and atypical temperature value can be eliminated or restrained using the monthly and annual average data, which can be used to show the urban heat island effect better [12]. Thus, we used the annual average LST. Different studies on the impact of urbanization and other factors on SUHII may have different results [43-45]. There are many methods that can be used, but the results will always be different. Oke (1973) had reported that there was a clear correlation between city size (as defined by urban population) and the UHI [11]. Clinton and Gong (2013) found that the population and urban structure indices were of lesser importance for urban heat island intensity [28], which is consistent with our study. Different studies also have various results even in the same area [46-49]. These SUHII value gaps are largely due to the influence of data source, accuracy, time range, and spatial resolution. The majority of SUHII values were between $0.0^{\circ} \mathrm{C}$ and $5.0^{\circ} \mathrm{C}$ in this study. In some 
special situations, a higher SUHII may appear in some cities in a certain period. For example, some results show that the average SUHII was $8.6-8.9^{\circ} \mathrm{C}$ in London (the average in 2000) [50] and $3-13^{\circ} \mathrm{C}$ in Tokyo (the 2001-2003 average) [51]. According to this study, the SUHII values of London and Tokyo were $2.0^{\circ} \mathrm{C}$ and $3.8^{\circ} \mathrm{C}$, respectively. In fact, the SUHII in a city is ever-changing and produces various readings over time, and so it is hard to compare results when these studies are done independently. Thus, it is necessary to analyze the SUHII under a uniform scale. Moreover, discontinuous urban spatial data are hard to directly analyze continuous LST data because global data resources limit the ability to observe and quantify this temporal process of urbanization and SUHII. Therefore, we adopt a concept of "space-for-time" to tentatively resolve the data problem.

From a viewpoint of statistics and matrix algebra, it is assumed that the development over time of a system under study is determined by the unobserved series with which a series of observations spatially is associated. The relation between unobserved series and observed series is specified by the space. The main purpose of space analysis is to infer relevant properties of unobserved series from observations [52]. In fact, the idea of space-for-time has always been used to infer past or future trajectories in previous studies [53]. Therefore, the theoretical foundation supports our analysis framework here.

\subsection{Various Urbanization Factors among Countries at Different Developmental Stages}

The spatial distribution of SUHII can be directly seen in our results and others', but the study results also imply the time differences of different development phases. In some developed countries, such as some European countries and the United States, which have higher urbanization levels and lower population growth rates, urbanization usually shows lower expansion rates in recent years. However, from a long-term perspective (decades), with the development of urbanization, the urban population, economy, and area will increase prominently, particularly in many developing countries. Take China as an example: along with fast economic growth, the scale of urbanization in China during the past 30 years is unprecedented and the urban population in China reached 51.3\% in 2011 [54]. To some degree, developed countries predict the future urban phases of developing countries. With uniform data and results, the different levels of developing and developed countries can be regarded as different development phases in one country or region.

We compared the results of China with those of the United States. SUHII was evidently related to population, GDP, urban area, and even shape index $S$ in China, while the results in the United States indicated that GDP was a more significantly related factor than population and urban area. Meanwhile, global major cities all indicated that population plays an important role in SUHII. Based on the urban proportions data, about $54.0 \%$ of the world's population was residing in urban areas in 2014, and the average annual rate of change from 2010 to 2015 was $0.9 \%$ [35]. The United States had more than $81.0 \%$ of the population living in urban areas and the average annual change rate from 2010 to 2015 was $0.2 \%$. China had $54.0 \%$ of the population living in urban areas and the average annual rate of change from 2010 to 2015 was $2.4 \%$ (Figure 6). We can suppose that the situations of the United States and China represent two typical situations, namely the high urbanization levels of a developed country and the low urbanization levels of a developing country. All in all, the global urbanization level is moderate. This implies that SUHII is more sensitive to almost all of the urbanization factors during the increasing phase. When urbanization is higher, population and GDP together play an important role in SUHII. When the urbanization level is very high and keeps increasing incrementally, urbanization may need urban land and population. In addition, the economy (GDP) has a strong influence on SUHII. Therefore, it can potentially keep the SUHII stable when urban development is under certain conditions (e.g., optimizing urban internal landscapes). Many new studies have proven that both vegetation types and water have a negative correlation with LST [7,14,28]. Moreover, vegetation growth enhancement may be prevalent in an urban environment because urban vegetation is usually influenced by urban greening, well management, and urban heat island, etc. [4]. 


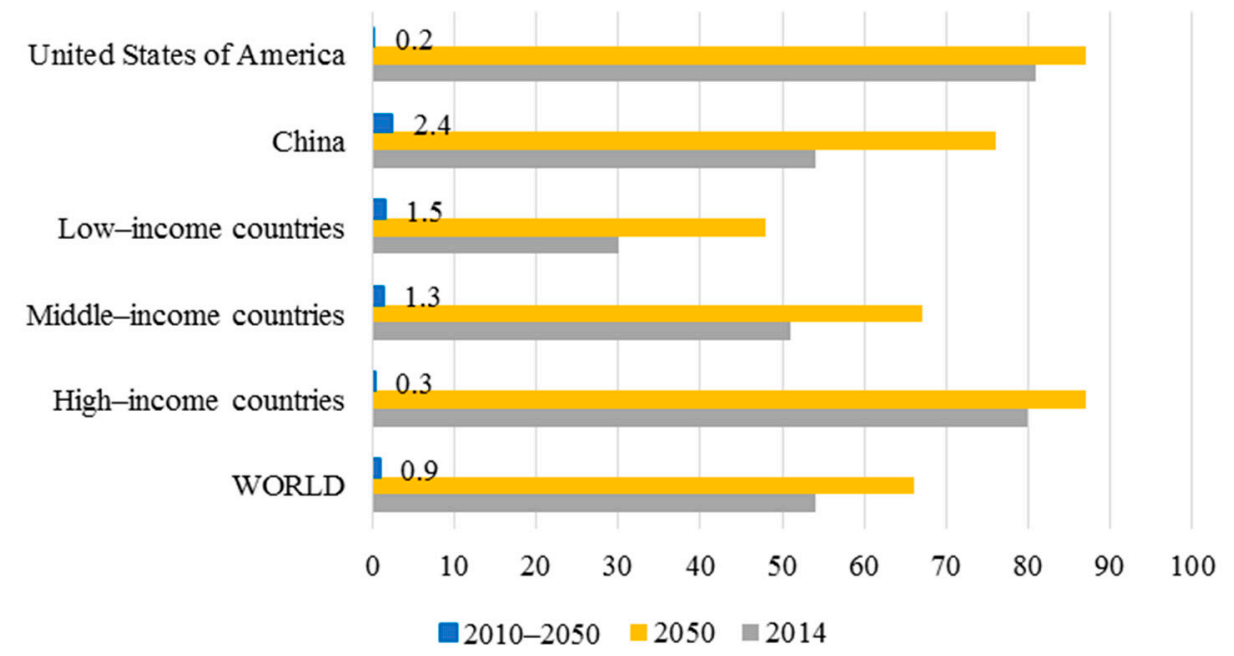

Figure 6. Urban proportion and the annual change rate of the urban population. Here, the blue blocks with numbers are the annual change rate of the urban population from 2010 to 2050; the gray and yellow blocks represent the urban proportion of 2014 and 2050, respectively. The country classification by income level is based on 2012 gross national income per capita from the World Bank. The data for China do not include Hong Kong and Macao, Special Administrative Regions (SAR) of China.

In this study, the concept of "space-for-time" used is not a method but an extensional expression of the results. In fact, this is a new exploration and tentative attempt using the concept in the research field. Although it can interpret the SUHII results and support the basic conclusion to some extent, it should be noted that, in the process of urbanization, there are various development styles in different regions, which could be related to more complex influence factors like landscape index, policy, and culture. The urbanization tracks at a large scale of geographical regions can potentially be similar but specific to a single city; there are still some uncertainties. Therefore, further studies are needed to validate this assumption in the future. Additionally, spatial data are used to analyze the LST and GDP differences between urban and rural areas, but statistical population data are based on the administrative boundary. Although the data is explicit when we link two-dimension spatial data, like remote sensing or geographic data, with one-dimension statistical data, the uncertainty is still hard to eliminate in the results.

\section{Conclusions}

This study analyzed the relationship between urbanization factors and SUHII, and some basic conclusions were obtained. From the perspective of space-for-time, no matter the urbanization phase, GDP, population, and area had important impacts on SUHII all the time, especially in major cities. The results also showed that the effects of population on SUHII might be large in the early urbanization stages, while the effects of GDP would become greater at higher urbanization levels. Urban spatial shape was of lesser importance in the urbanization process of major cities.

It seems that world urbanization will grow for at least the next several decades, and increasing population, GDP, and urban sprawl is a potentially unavoidable scenario. Given the situation, our study has important implications for future cities. It is important to consider the sustainability of cities with increased economy and population, both of which have important impacts on urban warming. However, based on our results, it is very likely that optimizing the spatial configuration of urban internal landscapes may be the best approach to keeping the SUHII stable when urbanization reaches a high level. 
Acknowledgments: This research was supported by the National Natural Science Foundation of China (No. 41401504 \& 41371409), the Chinese National Basic Research Program (No. 2014CB954302), and Key Scientific and Technological Projects of Henan Province (No. 152102310296). The authors would like to thank Jordan Woodward and Sadia Afrin from the University of Oklahoma for proofreading the paper. We are also grateful to the editor and the anonymous referees for their helpful comments and suggestions.

Author Contributions: Yaoping Cui and Xinliang Xu performed programming work, analysis, and discussions, and Yaoping Cui wrote most sections of the manuscript. Xinliang Xu, Jinwei Dong, and Yaochen Qin supplied suggestions and comments for the manuscript. All authors reviewed and polished the manuscript.

Conflicts of Interest: The authors declare no conflict of interest.

\section{References}

1. Schneider, A.; Friedl, M.A.; Potere, D. A new map of global urban extent from MODIS satellite data. Environ. Res. Lett. 2009, 4, 1-11. [CrossRef]

2. Cui, Y.P.; Liu, J.Y.; Hu, Y.F.; Wang, J.B.; Kuang, W.H. Modeling the radiation balance of different urban underlying surfaces. Chin. Sci. Bull. 2012, 57, 1046-1054. [CrossRef]

3. Seto, K.C.; Reenberg, A.; Boone, C.G.; Fragkias, M.; Haase, D.; Langanke, T.; Marcotullio, P.; Munroe, D.K.; Olah, B.; Simon, D. Urban land teleconnections and sustainability. Proc. Natl. Acad. Sci. USA 2012, 109, 7687-7692. [CrossRef] [PubMed]

4. Zhao, S.Q.; Liu, S.G.; Zhou, D.C. Prevalent vegetation growth enhancement in urban environment. Proc. Natl. Acad. Sci. USA 2016, 113, 6313-6318. [CrossRef] [PubMed]

5. Liu, J.Y.; Zhan, J.Y.; Deng, X.Z. Spatio-temporal patterns and driving forces of urban land expansion in China during the economic reform era. Ambio Chin. 2005, 34, 444-449. [CrossRef]

6. Myint, S.W.; Zheng, B.J.; Talen, E.; Fan, C.; Kaplan, S.; Middel, A.; Smith, M.J.; Huang, H.P.; Brazel, A.J. Does the spatial arrangement of urban landscape matter? Examples of urban warming and cooling in Phoenix and Las Vegas. Ecosyst. Health Sust. 2015, 1, 1-15. [CrossRef]

7. Alavipanah, S.; Wegmann, M.; Qureshi, S.; Weng, Q.; Koellner, T. The role of vegetation in mitigating urban land surface temperatures: A case study of munich, germany during the warm season. Sustainability 2015, 7, 4689-4706. [CrossRef]

8. Zhou, L.M.; Dickinson, R.E.; Tian, Y.H.; Fang, J.Y.; Li, Q.X.; Kaufmann, R.K.; Tucker, C.J.; Myneni, R.B. Evidence for a significant urbanization effect on climate in China. Proc. Natl. Acad. Sci. USA 2004, 101, 9540. [CrossRef] [PubMed]

9. Pickett, S.T.A.; Cadenasso, M.L.; Grove, J.M.; Nilon, C.H.; Pouyat, R.V.; Zipperer, W.C.; Costanza, R. Urban ecological systems: Linking terrestrial ecological, physical, and socioeconomic components of metropolitan areas. Annu. Rev. Ecol. Syst. 2001, 32, 127-157. [CrossRef]

10. Kellerman, A.; Krakover, S. Multi-sectoral urban growth in space and time: An empirical approach. Reg. Stud. 1986, 20, 117-129. [CrossRef] [PubMed]

11. Oke, T.R. City size and the urban heat island. Atmos. Environ. 1973, 7, 769-779. [CrossRef]

12. Jones, P.D.; Groisman, P.Y.; Coughlan, M.; Plummer, N.; Wang, W.C.; Karl, T.R. Assessment of urbanization effects in time series of surface air temperature over land. Nature 1990, 347, 169-172. [CrossRef]

13. Bottyán, Z.; Unger, J. A multiple linear statistical model for estimating the mean maximum urban heat island. Theor. Appl. Climatol. 2003, 75, 233-243.

14. Gusso, A.; Cafruni, C.; Bordin, F.; Veronez, M.R.; Lenz, L.; Crija, S. Multi-temporal patterns of urban heat island as response to economic growth management. Sustainability 2015, 7, 3129-3145. [CrossRef]

15. Weng, Q.H.; Lu, D.S.; Schubring, J. Estimation of land surface temperature-vegetation abundance relationship for urban heat island studies. Remote Sens. Environ. 2004, 89, 467-483. [CrossRef]

16. Yuan, F.; Bauer, M.E. Comparison of impervious surface area and normalized difference vegetation index as indicators of surface urban heat island effects in Landsat imagery. Remote Sens. Environ. 2007, 106, 375-386. [CrossRef]

17. Cao, X.; Onishi, A.; Chen, J.; Imura, H. Quantifying the cool island intensity of urban parks using ASTER and IKONOS data. Landsc. Urban Plan. 2010, 96, 224-231. [CrossRef]

18. Essa, W.; van der Kwast, J.; Verbeiren, B.; Batelaan, O. Downscaling of thermal images over urban areas using the land surface temperature-impervious percentage relationship. Int. J. Appl. Earth Obs. Geoinform. 2013, 23, 95-108. [CrossRef] 
19. Li, J.; Song, C.; Cao, L.; Zhu, F.; Meng, X.; Wu, J. Impacts of landscape structure on surface urban heat islands: A case study of Shanghai, China. Remote Sens. Environ. 2011, 115, 3249-3263. [CrossRef]

20. Zhou, W.; Huang, G.; Cadenasso, M.L. Does spatial configuration matter? Understanding the effects of land cover pattern on land surface temperature in urban landscapes. Landscape Urban Plan. 2011, 102, 54-63. [CrossRef]

21. Zhou, W.; Qian, Y.; Li, X.; Li, W.; Han, L. Relationships between land cover and the surface urban heat island: Seasonal variability and effects of spatial and thematic resolution of land cover data on predicting land surface temperatures. Landsc. Ecol. 2014, 29, 153-167. [CrossRef]

22. Hunga, T.; Uchihama, D.; Ochi, S.; Yasuoka, Y. Assessment with satellite data of the urban heat island effects in Asian mega cities. Int. J. Appl. Earth Obs. Geoinform. 2006, 8, 34-48.

23. Nobis, M.P.; Jaeger, J.A.G.; Zimmermann, N.E. Neophyte species richness at the landscape scale under urban sprawl and climate warming. Divers. Distrib. 2009, 15, 928-939. [CrossRef]

24. Wessels, K.J.; Prince, S.D.; Malherbe, J.; Small, J.; Frost, P.E.; VanZyl, D. Can human-induced land degradation be distinguished from the effects of rainfall variability? A case study in South Africa. J. Arid Environ. 2007, 68, 271-297. [CrossRef]

25. Deng, X.Z.; Huang, J.K.; Lin, Y.Z.; Shi, Q.L. Interactions between climate, socioeconomics, and land dynamics in Qinghai province, China: A LUCD model-based numerical experiment. Adv. Meteorol. 2013, 297926, 1-9. [CrossRef]

26. Jin, M.; Dickinson, R.E.; Zhang, D. The footprint of urban areas on global climate as characterized by MODIS. J. Clim. 2005, 18, 1551-1565. [CrossRef]

27. Peng, S.; Piao, S.; Ciais, P.; Friedlingstein, P.; Ottle, C.; Bréon, F.M.; Nan, H.; Zhou, L.; Myneni, R.B. Surface urban heat island across 419 global big cities. Environ. Sci. Technol. 2012, 46, 696-703. [CrossRef] [PubMed]

28. Clinton, N.; Gong, P. MODIS detected surface urban heat islands and sinks: Global locations and controls. Remote Sens. Environ. 2013, 134, 294-304. [CrossRef]

29. Easterling, D.R.; Horton, B.; Jones, P.D.; Peterson, T.C.; Karl, T.R.; Parker, D.E.; Salinger, J.M.; Razuvayev, V.; Plummer, N.; Jamason, P.; et al. Maximum and minimum temperature trends for the globe. Science 1997, 277, 364-367. [CrossRef]

30. Gallo, K.P.; Owen, T.W. Satellite-Based Adjustments for the Urban Heat Island Temperature Bias. J. Appl. Meteor. 1999, 38, 806-813. [CrossRef]

31. Hansen, J.; Ruedy, R.; Sato, M.; Imhoff, M.; Lawrence, W.; Easterling, D.; Peterson, T.; Karl, T. A closer look at United States and global surface temperature change. J. Geophys. Res. 2001, 106, 23947-23963. [CrossRef]

32. Deng, X.Z.; Zhao, C.H.; Lin, Y.Z.; Zhang, T.; Qu, Y.; Zhang, F.; Wang, Z.; Wu, F. Downscaling the Impacts of Large-Scale LUCC on Surface Temperature along with IPCC RCPs: A Global Perspective. Energies 2014, 7, 2720-2739. [CrossRef]

33. Wan, Z.; Zhang, Y.; Zhang, Q.; Li, Z.L. Quality assessment and validation of the MODIS global land surface temperature. Int. J. Remote Sens. 2004, 25, 261-274. [CrossRef]

34. Ghosh, T.; Powell, R.L.; Elvidge, C.D.; Anderson, S. Shedding Light on the Global Distribution of Economic Activity. Open Geophys. J. 2010, 3, 147-160.

35. United Nations; Department of Economic and Social Affairs; Population Division. World Urbanization Prospects: The 2014 Revision, Highlights (ST/ESA/SER.A/352); United Nations: New York, NY, USA, 2014.

36. Cui, Y.P.; Qin, Y.C. The spatial distribution of global urban heat island intensity and the influence of urban sprawl. In Proceedings of the 2013 21st International Conference on Geoinformatics, Kaifeng, China, 20-22 June 2013.

37. Wang, J.K.; Wang, K.C.; Wang, P.C. Urban Heat (or Cool) Island over Beijing from MODIS Land Surface Temperature. J. Remote Sens. 2007, 11, 330-339.

38. Chen, J.; Ban, Y.F.; Li, S.N. China: Open access to Earth land-cover map. Nature 2014, 514, 434.

39. Elvidge, C.D.; Tuttle, B.T.; Sutton, P.C.; Baugh, K.E.; Howard, A.T.; Milesi, C.; Bhaduri, B.L.; Nemani, R. Global Distribution and Density of Constructed Impervious Surfaces. Sensors 2007, 7, 1962-1979. [CrossRef]

40. Liu, Z.F.; He, C.Y.; Zhou, Y.Y.; Wu, J.G. How much of the world's land has been urbanized, really? A hierarchical framework for avoiding confusion. Landsc. Ecol. 2014, 29, 763-771. [CrossRef]

41. Ridd, M.K. Exploring a V-I-S (Vegetation-impervious surface-soil) model for urban ecosystem analysis through remote sensing: Comparative anatomy for cities. Int. J. Remote Sens. 1995, 16, 2165-2185. [CrossRef] 
42. Weng, Q. Remote sensing of impervious surfaces in the urban areas: Requirements, methods, and trends. Remote Sens. Environ. 2012, 117, 34-49. [CrossRef]

43. Grover, A.; Singh, R.B. Analysis of urban heat island (UHI) in relation to normalized difference vegetation index (NDVI): A comparative study of Delhi and Mumbai. Environments 2015, 2, 125-138. [CrossRef]

44. Wong, P.P.; Lai, P.; Low, C.; Chen, S.; Hart, M. The impact of environmental and human factors on urban heat and microclimate variability. Build. Environ. 2016, 95, 199-208. [CrossRef]

45. Gallo, K.P.; Owen, T.W.; Easterling, D.R.; Jamason, P.F. Temperature trends of the US historical climatology network based on satellite-designated land use/land cover. J. Clim. 1999, 12, 1344-1348. [CrossRef]

46. Griggs, D.J.; Noguer, M. Climate change 2001: The scientic basis. Contribution of working group I to the third assessment report of the Intergovernmental Panel on Climate Change. Weather 2002, 57, 267-269. [CrossRef]

47. Li, Q.; Zhang, H.; Liu, X.; Huang, J. Urban heat island effect on annual mean temperature during the last 50 years in China. Theor. Appl. Climatol. 2004, 79, 165-174. [CrossRef]

48. Xie, Z.Q.; Du, Y.; Zeng, Y.; Shi, Y.F.; Wu, J.G. Impact of urbanization on temperature change in the Yangtze River delta. J. Geogr. Sci. 2007, 62, 717-727.

49. Shao, Q.Q.; Sun, C.Y.; Liu, J.Y.; Tao, F.L. Impact of urban expansion on meteorological observation data and overestimation to regional air temperature in China. J. Geogr. Sci. 2009, 64, 1292-1302. [CrossRef]

50. Kolokotroni, M.; Giridharan, R. Urban heat island intensity in London: An investigation of the impact of physical characteristics on changes in outdoor air temperature during summer. Sol. Energy 2008, 82, 986-998. [CrossRef]

51. Yokobori, T.; Ohta, S. Effect of land cover on air temperature involved in the development of an intra-urban heat island. Clim. Res. 2009, 39, 61-73. [CrossRef]

52. Durbin, J.; Koopman, S.J. Time Series Analysis by State Space Methods; Oxford University Press: Oxford, UK, 2012.

53. Blois, J.L.; Williams, J.W.; Fitzpatrick, M.C.; Jackson, S.T.; Ferrier, S. Space can substitute for time in predicting climate-change effects on biodiversity. Proc. Natl. Acad. Sci. USA 2013, 110, 9374-9379. [CrossRef] [PubMed]

54. Zhao, S.Q.; Zhou, D.C.; Zhu, C.; Sun, Y.; Wu, W.J.; Liu, S.G. Spatial and temporal dimensions of urban expansion in China. Environ. Sci. Technol. 2015, 49, 9600-9609. [CrossRef] [PubMed]

(C) 2016 by the authors; licensee MDPI, Basel, Switzerland. This article is an open access article distributed under the terms and conditions of the Creative Commons Attribution (CC-BY) license (http://creativecommons.org/licenses/by/4.0/). 